\title{
Commercialization of Agriculture and Role of Agricultural Extension
}

\author{
Rohana P Mahaliyanaarachchi, R M A S Bandara \\ Sabaragamuwa University, Belihuloya
}

\begin{abstract}
Today commercialization of agriculture is an inevitable reality throughout the whole world. There are a number of factors affecting the commercialization process in agriculture. Some of them could be named as rapid growth of economies in the both developing and developed countries, introducing of new technologies, market expansion, market liberalization, urbanization, rapid increase of demand for food, decreasing of farming population, liberalized and open economic policies, bilateral and multilateral economic agreements, developed infrastructure facilities in farming areas and government agricultural policies. However, commercialization in agriculture is not a new phenomenon and it is not a surprise to the farming community. Since the nineteen fifties, farmers in most of the countries have moved towards commercial agriculture. Their major objective was surplus production aiming market prospects. Agricultural extension plays a major role in agricultural production.
\end{abstract}

Role of agricultural extension in a commercialized agricultural system is different from such service in subsistence farming system. In the commercialized agriculture the extension service will mainly concentrate on the resourceful big farmers, with favorable environmental conditions and higher socio-economic status. Under the commercialized agriculture the number of farmers is to be reduced and the size of the farm land should be increased. This is a generally accepted concept in commercial agriculture. Do we have to accept this concept under each and every situation? We think the answer is "no". By using improved technologies farmers can move towards commercial agriculture without considering the size of land. Under protected agriculture, farmers follow concepts of the commercial agriculture. Commercial livestock farming does not rely on the farm size except diary farming.

However, the role of agricultural extension in the commercialized agricultural system is mainly dependent on the type and way of commercialization in a given society. We have to expect that agricultural extension services are supposed to fulfill many aims, from reducing rural poverty and improved livelihoods for rural households to increasing the overall production and contributing to foreign exchange earnings from exports. But the level and percentage of this contribution may vary from one situation to another.

\section{Introduction}

Could we imagine that today a full time farmer produces only for the consumption of his family? There may be part time farmers who produce for their own consumption and as fun. It is a fact that a higher majority of farmers produce by aiming the market. Competition among farmers is increasing. Farmers who are not capable enough to survive in this high competition are being eliminated from the farming business. This is why farming population throughout the world is diminishing. There is a famous saying in Sri Lanka "do farming without knowhow, but for business it is a must". But this is not valid today, because farming is a big business. Therefore, it is not enough to have knowledge in farming or cultivation practices only. A successful farmer must have a broader knowledge 
and skills in management, ICT, marketing and entrepreneurship. Productivity plays the major role in farming business as other businesses.

\section{Concept of Commercialization}

What do we understand by commercialization of agriculture? Can we use marketable surplus of produce as a measure of commercialization?

\section{Marketable Surplus of Produce as a Measure of Commercialization}

The term marketable surplus in the context of agricultural produce denotes the quantities of products available for consumption by the non-farming population and also as raw materials for manufacturing and processing industries. This concept helps to measure the extent of commercialization of the production activities of a particular crop. While high proportions of marketable surpluses indicate greater market orientation of the producers, lesser proportions of surpluses mean that the producers are more subsistence-oriented. The Food and Agriculture Organization (FAO) has categorized farmers into three different groups based on the marketable surplus as a percentage of total production in the following manner (FAO, 1989) :

- Subsistence farmers: Marketable surplus under $25 \%$ of the total production.

- Transition farmers: Marketable surplus ranging between $25-50 \%$ of total production.

- Commercial farmers: Marketable surplus more than $50 \%$ of the total production

However, what do we understand by the term 'Commercialization of agricultural production?' It can be defined as follows.

- $\quad$ Farmers' production is aimed mainly for sales.

- Production should be oriented to profit maximization.

- It should aim at the satisfaction of different needs and interests of consumers.

- It is an agri -business that implies concept of business management.

- It leads to entrepreneurial achievements of farmers.

\section{What is the definition of 'Agricultural Extension'?}

Mahaliyanaarachchi (2003) gives the following definition :

'Agricultural Extension is an ongoing, non-formal educational process which occurs over a period of time and it leads to improve the living conditions of farmers and their family members by increasing the profitability of their farming activities. In this activity, to achieve above goals, it expects the improvement of the farmer's knowledge, skills and change of their attitudes in agricultural technology, farming activities and agricultural marketing.' 
Is this definition valid for today under the commercialization of agriculture? Is it only an educational process or more than that? Isn't it a socio-economic process? Is it not a business than a free service?

Today extension should look into increasing the productivity of the farming business as a whole. It includes both direct farming activities and off farm or farming related activities. Agricultural extension should assist, guide and direct farmers to identify both farming and non-farming activities which can increase their net income.

Therefore, the mode of agricultural extension is also a key factor which affects the degree of commercialization of agriculture. Today, agricultural extension is a commodity with a certain price. This commodification of agricultural extension, the transforming of knowledge into a product for sale, helped to revolutionize both public sector extension and the business of private sector technology transfer (Rivera 2000). This revolution took place not because of anything else, only because of the commercialization of agricultural extension.

\section{Concept of Commercialization of Agricultural Extension}

What do we understand by commercialization of agricultural extension?

Under this concept, first, agricultural extension is considered as a commercial product or service, which exchanges between two parties over a required payment. Simply one party (extension providers) acts as sellers and other party (farmers) acts as buyers. Secondly, basic economic theory of supply and demand is applied in this process. Agricultural extension service becomes a totally demand-oriented activity. Thirdly, extension can also be considered as an input such as fertilizer, improved seed, agro-chemicals, machinery, etc, which is essential for the commercially oriented farming. As farmers have to pay for other inputs, they have to pay for extension services also.

The basic concept is that farmers have to pay for the service which they get. Either farmers pay totally or partially, it depends on the extension approach. Farmers may pay the full amount of the fee or the government or other funding agency could subsidize it fully or partially. However, finally extension providers are being paid for their service. These extension providers are not essentially to be private sector companies or individuals. It can be a government or semi government extension agency.

\section{Why Commercialization, not Privatization?}

Privatisation is mainly changing the ownership of the extension service to private sector from public sector. Extension services have been mainly funded and delivered by government agencies free of charge for decades. People in most of the developing countries have unpleasant experiences of privatization. This is why the concept of commercialization came into picture.

Commercialization is not merely privatisation. It does not need a change of ownership under commercialization. Ownership can be kept with the government 
or semi government organization, but the service is provided on a commercial basis. Under privatization, ownership should be changed into the hands of a private organization.

\section{Different Approaches of Commercialization of Agricultural Extension}

There are a number of extension approaches that can be listed. Here, I would like to categorize them into following groups.

- Decentralization

Decentralization of agricultural extension refers to one way of gradual transfer of responsibility for extension from the public to the private sector. It involves the transfer of planning, decision making, management, from the central government and its agencies to field organizations, subordinate units of government, semiautonomous public organizations, regional organizations, chambers of commerce, and even non governmental organizations.

- Public cost recovery approach

To cope with serious fiscal constraints and by changing structure of the farming sector, most of the governments have begun charging fees for some extension services they provide to the rural sector. The degree to which these cost recovery programs have been pursued has varied across countries.

- Totally private extension delivery approach

The major idea of this is to transfer delivery of extension services mainly to the private sector. Several types of private firms currently undertake agricultural extension activities. These include agro-processing firms, input suppliers, media companies and consulting firms.

- Contracting of extension services

There are two types of extension contracting viz. "contracting out" and "contracting in". Contracting out means public sector or state provides financing and private sector delivers the extension service for the financing authority. Contracting in means private organization or an NGO provides funds and public sector organization delivers the extension service.

- Farmer taxation

Farmers are taxed for the services provided to them directly or indirectly. For instance in Sri Lanka, tea small holders are taxed indirectly for the extension services provided to them through Tea Small Holders Development Authority which is a semi government body.

- Pluralism

Pluralism or pluralistic extension system means using both public and non-public institutions for delivering extension services to farmers (Qumar, 2001). In many developing countries, various non-governmental organizations, private input supplying companies, semi governmental organizations deliver extension services parallel with the public sector extension services.

\section{Role of Agricultural Extension in Commercialized Agriculture}

Role of agricultural extension in a commercialized agricultural system is different from such service in a subsistence farming system. In the commercialized agriculture the extension service will mainly concentrate on the resourceful big farmers, with favorable environmental conditions and higher socio-economic status. Under commercialized agriculture, the number of farmers is to be reduced 
and the size of the farm land should be increased. This is a generally accepted concept with regard to commercial agriculture. Do we have to accept this concept under each and every situation? I think the answer is "no". By using improved technologies farmers can move towards commercial agriculture without considering the size of land. Under protected agriculture, farmers follow concepts of commercial agriculture. Commercial livestock farming does not rely on the farm size except diary farming.

However, the role of agricultural extension in the commercialized agricultural system is mainly dependent on the type and way of commercialization in a given society. As in the past, today also we have to expect that agricultural extension services are supposed to fulfill many aims, from reducing rural poverty and improved livelihoods for rural households to increasing the overall production and contributing to foreign exchange earnings from export (Haug, 1999). But the level and percentage of this contribution may vary from one situation to another.

Agricultural extension services in commercial agriculture would essentially depend on the type and quality of services made available by different commercial extension service agencies, information needs of the farmers and their willingness to pay for extension services (Sulaiman and Sadamate, 2000). The quality of the extension service depends on a number of factors such as timeliness, amount of the information, innovativeness, understandability, trustworthiness and economic and technical feasibility. Unlike subsistence farmers, commercial farmers look for profitability of the technology introduced by the extension service. They pay for the service that they get.

In commercial agriculture, extension advice is also considered an input. In the industry when a factory owner wants to get the technology he has to pay for it. As it is in commercial agriculture which is considered as an industry, the farmer (owner of the industry) has to pay for the technical advice/s he needs for the profitability of the industry. Commercial agriculture is a competitive business. Farmers who do not implement profit maximization technologies and techniques cannot survive for long.

However, we totally agree that the type of extension service should be decided mainly based on the state of agricultural development in the country. Also, even in a developed economy there are several technologies that are inevitably public goods such as soil conservation technologies, environmental protection technologies etc. In commercial agriculture, farmers require a more individually tailored problem solving service. Such information should be excludable and in high quality. Then only farmers are willing to pay for it. In the short term, extension information becomes excludable because the majority of farmers do not receive the same at the same time due to slow speed of information dissemination. However, most of the information on agricultural technologies in the long term will not be excludable. Nevertheless, a considerable amount of agricultural extension information such as fertilizer, seed, planting material, agro chemicals, machines, farm budgeting, farm planning, etc., are considered as private goods and commercialized extension service can adequately cater to this type of requirements. A commercialized extension service can deliver both public and private goods simultaneously. They can charge for private goods while public goods can be provided free of charge. By this they can win the goodwill and trustworthiness of the farming community. 
Commercialized agricultural extension is inevitably efficient and effective than a state owned, free of charge extension service because if it is not efficient and effective, the life time of such service is very short. It is more demand - driven rather than supply - driven. Further, better competition among commercial agencies could help to improve the quality of the service. The better flexibility in decision making and program implementation in commercial agencies will be an important factor for their high effectiveness. Unlike a government owned free of charge extension service, a commercialized service specifically caters according to the specific needs of the clientele. It is an inevitable factor that agricultural extension in commercialized agriculture should be of high quality in terms of satisfying information needs of the clientele. Also there should be better competition among private agencies for products.

Commercialization of agricultural extension is not popular yet, but privatization of agricultural extension is experienced by a number of developed and developing countries in the world. Privatization of agricultural extension is a type of commercialization of extension and today it is a highly practiced one among other commercialized extension methods. It is better to examine the lessons out of their experiences. Some of the important lessons out of international experiences (Ameur, 1994; Qumar, 2000; Rivera, 1996; Rivera, 1992) are:

- Private Extension reduces the economic burden of the governments and increases the efficiency of extension services provided - Netherlands;

- Government has perfect control over Private Extension - Chile;

- Personal economic interest of the extension agent mixed with his increase of professional involvement in extension activity - share cropping in Ecuador;

- Privatization increases the accountability of extension agent - Extension contract system in China;

- It is possible to prevent the farmers being exploited by private extension agents by proper legislation - Denmark;

- Private Extension is cost effective compared to public extension due to low overhead charges -United Kingdom;

- Certification and grading of technical consultants is possible for regulation Germany;

- Government can focus on sustainable areas, leaving regular extension to private extension -Tunisia;

(Sadighi, 2004)

\section{Challenges Faced by Agricultural Extension Today in Commercial Agriculture}

Agricultural extension in most of the countries both in the developing and developed world faces a number of challenges today due to rapid commercialization of agriculture. Agriculture is no more just farming. It is a business. Today agriculture includes not only production but also post harvest activities, processing, marketing, advertising and market promotions, information communication technology, etc. In commercialized farming, new and improved technology becomes an inevitable input which is a major factor in high productivity.

So, it is important to examine what the challenges faced by agricultural extension today in commercial agriculture sector are. They can be listed as follows: 
1. Agricultural information including marketing and planning becomes excludable in the short term due to differences in speed of information dissemination.

2. Due to the nature of face-to-face contacts (person oriented and advisory type) poor and resourceless farmers will be ousted from the mainstream of extension. There will be greater chances of overlooking poor.

3. Farmers will be more dependent on extension service because it would involve input such as fertilizer, chemicals, machinery, etc. This over dependency would reduce the creativity of farmers.

4. Extension service in commercial agriculture is a business rather than a service. Therefore, competitive companies may disseminate contradictory messages through advertisements. These publicity techniques may lead to unnecessary confusion. Commercial advertisements tend to be deceptive, rather than informative in areas like sale of seeds, chemicals, fertilizer, machinery and other equipment.

5. Profit oriented commercialized extension services will not deal effectively with poor farmers. Resource-poor or small-scale farmers will be neglected by these extension services. They will consider only rich and large or medium scale farmers who can afford their services. Poor farmers who cannot pay for the extension service will be eliminated automatically from the system.

6. This negligence of resource-poor farmers may lead to crucial socioeconomic problems. They may leave farming and increase ruralurban migration. While low industrial development of these developing countries cannot satisfy the needs of these migrants, urban unemployment will increase rapidly.

7. These commercial organizations do not pay sufficient attention to the environmental issues. Their main attention is to satisfy clients' needs by introducing most economical ways and methods. They do not care whether it is environmental-friendly or not. So, environmental degradation will be increased due to unsustainable and harmful technologies.

Now, the main question is whether commercial agricultural extension service can overcome these challenges. A totally privatized extension service can hardly overcome these challenges. Nevertheless commercial agricultural extension service with public- private partnerships may be able to overcome some of these challenges. As we know there are totally public goods which are very essential for the sustainability of agricultural production such as soil conservation techniques, integrated pest management techniques etc. In commercial agriculture, commercialized extension service should clearly identify and be able to differentiate between public and private goods. Then they should have a policy regarding dissemination of knowledge in relation to both public and private goods. There is no question about exchanging private goods for a fee. Public goods cannot be sold. Extension service has to disseminate both goods to the farmers but one for a fee and other for free of charge. So, both cost effectiveness and efficiency of the service depend on the strategies used by the extension organization.

For commercialized extension services to play a role in commercial agricultural development overall, it is necessary to consider how they can complement and 
improve existing efforts in the area of extension. In addition, it is fundamental to recognize that the objectives of commercial extension activities are not the same as those of totally state owned public extension services.

To overcome these challenges, the combining of commercial and free of charge extension (may be state owned or NGO operated) services can be a useful strategy. Public and private organizations provide different types of information. For example, a farmer may want to try out new low input methods on a small area of his farm and continue with traditional methods on the rest. The public extension service can provide expertise on low input sustainable agriculture methods, and the other improved input sales representative will provide information on the use of them. However, both can make an influence on the farmer's decision-making process.

With the development of the commercial extension sector, the role of free of charge extension services may change. In many developed countries, government agricultural services focus on regulation, the environment, and continued provision of advisory services in collaboration with the commercial extension services sector to groups left out by them.

Countries with large subsistence-farming sectors or resource-poor farmers may need to focus on alternative extension strategies. Extension services provided by the state sector and non profit oriented NGOs in these countries should organize programs to help resource-poor farmers. Again same problems arise in state owned extension services such as lack of funds, bureaucratic inefficiency, inappropriate strategy and lack of accountability. Extension services provided by NGOs have problems regarding their sustainability. Most of these services are short term and survive until funding agencies provide funds.

However, in general, the state owned free of charge extension services should concern themselves with these resource-poor farmers that the commercial extension service sector undersupplies because there are no appropriable benefits. It is important to recognize that resource-poor farmers, traditionally risk averse, can be eager to innovate when a clearly profitable opportunity presents itself. Nevertheless they are generally in the late majority group.

Most of the profit-oriented extension services do not pay sufficient attention to the environmental issues. However, this situation is changing in developed countries while the civil society in these countries pays better attention to environmental issues. Nevertheless, still the developing countries have very minimum attention on these issues. Therefore, public sector extension may focus on these environmental issues.

Existence of both public and private extension systems in a country offers competing, conflicting and overlapping extension programs. It was found that in a number of South Asian countries, both private and public extension rely on a strategy of using contact farmers, which severely limits the diffusion of information. Commercialized sector is more concerned with serving the needs of larger, resource-rich farmers to the exclusion of other farmers because of its primary interest in generating profits.

However it is an important issue to pay urgent attention to in rethinking extension strategies so as not to worsen the growing information gap between rich and poor farmers. 


\section{Conclusion}

Commercialization of agricultural extension becomes a reality today. Therefore we cannot survive only with free of charge extension services which are mainly owned by the government sector. Today most of new technologies are developed by research institutes and/or commercial firms by spending a large cost. As an example, a new variety of paddy or maize was developed by spending millions of dollars. Today most of these research institutes or commercial firms are profit-oriented institutes. They are not prepared to give this technology free of charge. Therefore, commercial extension service has to purchase it and sell back to the farmers.

But this is not the reality in the farming world. There are millions of resource-poor farmers in the developing countries. They will be marginalized by commercialized extension services and therefore a number of social problems may arise. So, the state owned free of charge extension services should concern themselves with these resource- poor farmers.

Considering all these facts discussed throughout this paper, the role of extension in commercial agriculture can be summarized as follows:

- Durability of the service depends on quality, effectiveness and efficiency.

- The extension service should provide information and advice not only on cultivation practices, but also in farm planning and management, post harvest practices and management, marketing and alternative income generating sources and technologies.

- Information and knowledge delivered by the extension service should be cost effective. Else, the sustainability of the service would be in danger.

- Commercialized extension service should identify alternative strategies not to marginalize resource-poor farmers in the community.

- Extension service should provide a number of alternative recommendations rather than a package. Then farmers can select the best solution or recommendation out of the alternatives.

- Delivery of public goods is a problem because they are nonexcludable and non-rival. Also, many types of agricultural information are not pure public or private goods: information may be highly excludable but at the same time non-rival within that group. Extension service has to identify new methods to deliver this type of goods, because these cannot be delivered for a fee.

- They have to pay sufficient attention to environmental issues, not merely increase productivity. One of the major criticisms against commercialized extension services is trying to increase productivity without considering environmental issues which is very important for the sustainability and balance of the environment. 


\section{References}

Ameur, C. 1994. 'Agricultural Extension: a step beyond the next step'. World Bank Technical Paper No. 247. The World Bank, Washington, DC.

Food and Agricultural Organization.1989. 'Horticultural marketing : a resource and training manual for extension officers', Rome.

Haug. R. 1999. Some leading issues in international agriculture: a literature review. The Journal of Agricultural Education and Extension, Vol. 5, pp 263-274.

Mahaliyanaarachchi, R.P. 2003. Basics of Agricultural Extension, Colombo : Godage International Publishers.

Qumar, M. K. 2000. 'Agricultural Extension at the Turn of the Millennium: Trends and Challenges'in Human Resources in Agricultural and Rural Development, Rome: Food and Agricultural Organization.

Qamar M. K. 2001. http:// www. Fao.org/DOCREP/003/X7925M /X7925 M15.htm Rivera, W M. 1992. Decentralizing Agricultural Extension, Alternative Strategies. International Journal of Lifelong Education 16.5, October, pp393-402.

Rivera, W. M. 1996. Agricultural Extension in Transition World; structural, financial and managerial strategies for improving agricultural extension. Public administration and Development, Vol. 16, pp151-161.

Rivera, W.M. 2000. The Changing Nature of Agricultural Information and the Conflictive Global Developments Shaping Extension. Journal of Agricultural Education and Extension (Wageninen), 7:1, June 2000, 31-41.

Sadighi, H. 2004, Proceedings of the 20th Annual Conference, AIAEE 2004, Dublin.

Sulaiman, R. V. and Sadamate, V.V. 2000. Privatizing Agricultural Extension in India. Policy Paper 10, NCAP, New Delhi. 